\title{
A aliança indissociável entre o turismo cultural e o turismo em espaço rural na Madeira
}

\author{
The inseparable alliance between cultural and rural tourism in Madeira
}

\section{Elisabete Rodrigues}

Instituto Politécnico de Portalegre, Praça da República, no 23-25, 7300-109 Portalegre, Portugal, elisabete.rodrigues1@gmail.com

\section{Resumo}

O turismo e a cultura são aceites como áreas estratégicas na esfera do crescimento económico e social de muitas regiões e sendo o património cultural da Madeira um fator de forte atratividade turística no contexto do turismo em espaço rural (TER) na llha, pretendeu-se neste artigo demonstrar a necessidade de valorização da dimensão cultural como recurso turístico fundamental na oferta turística futura das "Casas de Campo» na Ilha da Madeira. A metodologia incluiu, para além da pesquisa bibliográfica, a condução de inquéritos aos visitantes das "Casas de Campo» na Ilha, assim como de entrevistas semiestruturadas dirigidas aos proprietários/representantes destes empreendimentos. Um dos principais contributos da presente investigação residiu na constatação da aliança indissociável entre o turismo cultural e o turismo em espaço rural na Ilha, e na consequente e iminente inclusão da vertente cultural como recurso turístico nas futuras estratégias promocionais do TER na Madeira.

Palavras-chave: Turismo rural, turismo cultural, casas de campo, Madeira.

\section{Abstract}

Tourism and culture are acknowledged as strategic areas in the context of many region's economic growth and since Madeira's cultural heritage proved itself a key factor of tourist attraction in Madeira's Rural Tourism framework, this article intended to demonstrate the need to value the cultural dimension as a fundamental tourist resource for the future offer of Madeira Island's Country Homes. The methodology includes, besides the bibliographical research, the conduction of surveys to visitors of the Island's Country Homes, as well as semi-structured interviews directed to these establishment's owners/representatives. The results of the study reveal the inseparable alliance between the Island's cultural and rura tourism, highlighting the imminent inclusion of the cultural dimension as a tourist resource in future promotional strategies for Rural Tourism in Madeira.

Keywords: Rural tourism, cultural tourism, country homes, Madeira.

\section{Introdução}

Portugal considera o turismo como um setor estratégico no desenvolvimento da sua economia, sendo a Madeira uma das principais áreas recetoras de turistas do país. Em contrapartida, o turismo cultural tem vindo a assumir uma relevância particular na oferta turística de qualquer destino turístico.

No último quartel do século $X X$, o turismo era um setor em crescimento e num cenário caraterizado pelo êxodo rural, o turismo em espaço rural (TER) emergiu, quer no espaço europeu, quer em Portugal como uma forma de solucionar um conjunto de dificuldades (Hernandez-Maestro \& González-Benito, 2013), apesar da sua génese remontar à época da Revolução Industrial (Perales, 2002). A sua implementação potenciaria a fixação das populações e o desenvolvimento económico nas zonas rurais, assim como seria o propulsor ideal para a recuperação, preservação e valorização dos recursos patrimoniais e ambientais: "[A]credito no turismo, não como uma bandeira para o desenvolvimento, mas, como um potencial motor e veículo para esse desenvolvimento, que se quer integrado e valorativo dos componentes essenciais à construção equilibrada de um território: a sua população, o seu património (cultural e natural), e a economia" (Burnay, 2006, p. 167).

A Madeira é um destino turístico com tradição ancestral. Graças à sua posição geográfica e ao quadro atlântico europeu entre os séculos XV e XVIII, eclodiu em diferentes áreas "registando aspectos da sua geologia, fauna, flora, antropologia, orografia, clima e beleza paisagística" (Silva, 1985, p. 6), tendo-Ihe por isso sido atribuídos diversos epítetos, pelos quais ainda é conhecida na atualidade: "A llha dos Amores», "O Recanto do Paraíso», "A Pérola do Atlântico», entre outros. No momento presente, a oferta turística da llha é identificada na esfera internacional, essencialmente pelo seu património natural, pela hospitalidade dos madeirenses e pela segurança (GConsulting, 2005).
O turismo em espaço rural tem sido alvo de diferentes estudos no espaço de Portugal peninsular, que denunciam uma realidade distante dos objetivos preconizados inicialmente. Sobre o arquipélago da Madeira, existe apenas um estudo (Rodrigues, 2014), que à semelhança de Portugal peninsular, revela uma realidade análoga.

Por outro lado, nem as entidades responsáveis pela promoção turística da Madeira, nem os proprietários das "Casas de Campo» reconhecem a importância de uma promoção específica para o TER face à segmentação deste tipo de turismo e à heterogeneidade destes visitantes (Peña, Jamilena \& Molina, 2012).

A investigação para o presente artigo teve por base um projeto mais amplo, sobre a interligação entre o património e o turismo em espaço rural na ilha da Madeira. O presente artigo centrou-se no desenvolvimento do turismo no espaço rural na Madeira, com enfoque especial para a modalidade Casas de Campo e nas implicações da sua interligação com o turismo cultural, procurando contribuir para o conhecimento aprofundado do desenvolvimento do TER na llha.

Nesta perspetiva e em termos genéricos, foram definidos para a presente investigação os seguintes objetivos:

- Identificar o Perfil do Visitante que procura as Casas de Campo na ilha da Madeira, face à segmentação que domina os usufruidores do TER;

- Demonstrar a aliança entre o TER e o Turismo Cultural, com base na valorização das atividades culturais como recurso turístico fundamental na oferta turística futura das «Casas de Campo» na ilha da Madeira.

Partindo do princípio que as hipóteses são suposições ou soluções antecipadas do problema objeto da investigação que nos auxiliam 
a orientar a pesquisa, para o presente estudo foi lançada a seguinte hipótese:

- As motivações turísticas deste visitante não se fundamentam unicamente no património natural da llha. A procura pelo património cultural é uma realidade e retrata a aliança indissociável entre o Turismo Cultural e o TER.

Nesta linha de orientação, apresentámos o perfil deste visitante, com uma focagem particular nos fatores de motivação principais da visita e nas atividades desenvolvidas na Iha que nos permitiram constatar a aliança indissociável entre o Turismo Cultural e o TER e consequentemente a relevância de incluir a vertente cultural como recurso turístico nas estratégias promocionais futuras do TER na Madeira.

O artigo está organizado em diferentes partes. Na primeira parte abordámos a revisão da literatura; na segunda parte justifica-se a exposição da metodologia seguida no processo de investigação, constando a discussão dos resultados na terceira parte. A quarta e última parte, espelha as conclusões e os contributos futuros da presente investigação.

\section{Revisão da Literatura}

A revisão da literatura incluiu diferentes análises sobre a presente temática que se centraram nas áreas do turismo cultural e na do turismo em espaço rural e, em particular na interligação entre ambas.

O conceito de cultura é muito vasto, difuso e difícil de definir. Segundo Manuel Antunes este conceito tem sido discutido e delineado ao longo dos séculos (1999, p. 39). Annemarie Nicely e Sandra Sydnor defendem que a cultura deve ser entendida como "a resposta da comunidade perante o ambiente envolvente, a qual se manifesta frequentemente através das crenças e práticas partilhadas pela comunidade" (2015, p. 720). Numa perspetiva antropológica, Marujo e Ramos defendem que perante a natureza do fenómeno turístico, qualquer tipo de turismo é cultural (2008, pp. 22-23). Esta opinião é igualmente defendida por David Crouch quando afirma que não existe nenhum tipo de turismo que não seja cultural (2013, p.22).

Tal como o conceito de cultura, o de turismo cultural também não é simples de definir. A Organização Mundial de Turismo (OMT) considera como turismo cultural as visitas ao património tangível, sempre que estas representem a principal motivação da viagem (WTO, 2006, p. 47).

Com base na complexidade de definir "cultura», concordamos com a opinião de Christian Maurer, quando afirma que a multiplicidade de definições de Turismo Cultural, reside numa panóplia de diferentes abordagens e pontos de vista (2015, p. 231).

Roberto Reis corrobora este parecer ao afirmar que o Turismo Cultural não se cimenta em motivações turísticas, relacionadas apenas com eventos ou experiências culturais: "Antes circunscrever-se-á numa espécie de geometria triangular, a qual envolve, para além dos aspetos culturais patrimoniais, a fruição de valores patrimoniais culturais, assim como um mosaico de atividades ligadas à prática do turismo" (2013, p. 297).
As vantagens da interligação entre turismo e cultura têm sido muito defendidas, quer na ótica do turismo como um dos condutores primordiais nas trocas culturais (ICOMOS, 1999), quer na "perspectiva de consolidação de uma competitividade duradoura, cujos pilares sejam a qualidade, a sustentabilidade, a diferenciação, a autenticidade, uma conjunção coerente de produtos tradicionais e de produtos modernos" (Carvalho, Batista \& Costa, 2010, p. 246).

Admitindo-se que o enriquecimento da oferta turística equacionado com o desenvolvimento das tradições e da oferta cultural de uma região para além de contribuir para a recuperação e preservação do património cultural, pode ser um fator relevante de diferenciação e de competitividade para o TER (Batista \& Ferreira, 2010; MacDonald, \& Jolliffe, 2003), urge investigar se os recursos culturais, apresentam uma forte atratividade turística no contexto do turismo em espaço rural na llha, uma vez que "cultura não é um facto residual ou neutro relativamente à economia. Ao invés, ela é uma parte integrante e pode mesmo constituir-se como um dos seus motores de desenvolvimento" (Henriques, 2008, p. 29).

O património cultural de uma região encerra componentes, com dimensões tangíveis e intangíveis cuja importância é cada vez maior no desenvolvimento das políticas regionais do turismo. Neste contexto, em 2015, na "UNWTO/UNESCO World Conference on Tourism and Culture: Building a New Partnership" retiraram-se algumas conclusões que importa referir. Segundo Alfredo Pérez de Armiñán, Assistente do Diretor-geral para a Cultura, UNESCO: “Cultura e turismo são indissociáveis. [...] O turismo desempenha um papel essencial na valorização e salvaguarda da cultura" (UNWTO/UNESCO, 2015). Já em 2006, na "UNWTO International Conference on Cultural Tourism and Local Communities» ficara claramente reconhecido que o património intangível, numa perspetiva local, incluía elementos essenciais para um melhor entendimento por parte do visitante sobre o estilo de vida e a cultura da comunidade visitada (WTO, 2006, p. 8).

O encadeamento entre o turismo cultural e o turismo em espaço rural está claramente patente na legislação portuguesa, em particular na apresentação da noção de empreendimento no espaço rural, quando no ponto 1 , do art. 18 da republicação do Decreto-Lei no 39/2008, de 7 de março, através do Decreto-lei no 15/2014 de 23 de janeiro, refere que os empreendimentos de turismo em espaço rural devem preservar, recuperar e valorizar "o património arquitetónico, histórico, natural e paisagístico dos respetivos locais e regiões onde se situam, através da reconstrução, reabilitação ou ampliação de construções existentes, de modo a ser assegurada a sua integração na envolvente".

Nesta arena de discussão, o turismo em espaço rural é outro conceito que tem apresentado diferentes definições (Bel, Lacroix, Lyser, Rambonilaza \& Turpin, 2015; Jepson \& Sharpley, 2015; Santana-Jiménez, Sun, Hernandez \& Suárez-Veja, 2015; Hernandez-Maestro. \& González-Benito, 2013; MacDonald \& Jolliffe, 2003). Segundo um esclarecimento da OMT, o "conceito de turismo rural inclui um número de elementos constitutivos, no centro dos quais se encontra a comunidade de turismo rural. $\mathrm{O}$ 
turismo rural depende daquilo que o meio rural tem para oferecer: património, cultura, atividades rurais e estilo de vida rural" (WTO, 2004a, p. 13).

Para Luigi Cabrini, Representante Regional da OMT para a Europa, o termo «turismo rural» é utilizado sobretudo quando a "cultura rural» é a componente chave do produto turístico oferecido por essa região (WTO, 2004a, p. 9). Em sua opinião, o que diferencia os restantes produtos turísticos do turismo em espaço rural "é o desejo de oferecer aos visitantes um contacto personalizado, a experiência da envolvente física e humana do meio rural e sempre que possível, facultar a participação ativa nas atividades, tradições e estilos de vida das populações locais" (WTO, 2004a, p. 9).

Ao compararmos os conceitos de turismo cultural e de turismo rural oferecidos pela OMT, verifica-se que os fatores de motivação turística espelham uma forte incidência no património cultural, que é a base do turismo cultural e que tanto o conceito internacional como o português retratam uma interligação profunda entre o turismo em espaço rural e o património cultural da região visitada, a qual tem sido tem sido igualmente defendida em estudos recentes sobre o turismo em espaço rural (Rid, Ezeuduji \& Pröbstl-Haider, 2014; Huang, Beeco, Hallo \& Norman, 2016; MacDonald, \& Jolliffe, 2003).

A noção de património sofreu uma grande evolução nos últimos tempos. Enquanto no passado, se resumia a um conceito essencialmente jurídico, designando os bens herdados dos progenitores, na atualidade é compreendido como um elemento identificador de um povo (Pérez, 2003; Carvalho, 2008). Gaspar Pereira considera que a crescente valorização do património é fruto de uma questão de sobrevivência humana, na tentativa de permitir a um povo a preservação da sua identidade e memória $(2009$, p. 77). Esta opinião foi igualmente defendida por Françoise Choay ao considerar que o património histórico se assemelha a um imenso espelho onde a humanidade pode contemplar a sua própria imagem (2008, p. 253), imagem essa que "pode ser interpretada como o refúgio das sociedades contemporâneas face a transformações de que não dominam nem a profundidade, nem a aceleração e que parecem pôr em causa a sua própria identidade" (2008, p. 253).

Foi este quadro de indissociabilidade entre o património cultural e o turismo em espaço rural, onde as comunidades rurais ganham relevância como "guardiães de patrimónios e de memórias" (Pereira, 2009, p. 78), frequentemente com superior grau de preservação (MacDonald \& Jolliffe, 2003) que nos motivou a delimitar quer o nosso objeto de estudo, quer o rumo da presente investigação, na tentativa de valorizar a inclusão da vertente cultural no futuro desenvolvimento do turismo rural (Nicely \& Sydnor, 2015, p. 727), na ilha da Madeira.

As últimas décadas têm presenciado alterações no perfil dos turistas, cada vez mais conhecedores e informados procuram complementar e enriquecer a sua experiência turística combinando diferentes atrações (Huang, Beeco, Hallo, \& Norman, 2016), desde o património natural ao cultural, na tentativa de descortinar e desfrutar de uma forma sofisticada, do espaço em que se encontram. Para satisfazer as expetativas destes visitantes, os mercados turísticos têm vindo a criar serviços e produtos turísticos especiais dirigidos essencialmente a nichos de mercado (WTO, 1997, p. 117).

\section{Metodologia}

\subsection{Contexto do Estudo}

Como referenciado anteriormente, a investigação para o presente artigo teve por base um projeto mais amplo. O presente artigo centrou-se no desenvolvimento do turismo no espaço rural na Madeira, com enfoque especial para a modalidade Casas de Campo e para as implicações da sua interligação com o turismo cultural, procurando contribuir para o conhecimento aprofundado do desenvolvimento do TER na Ilha.

A oferta turística da llha é identificada na esfera internacional, essencialmente pelo seu património natural, pela hospitalidade dos madeirenses, pelo clima e pela segurança (GConsulting, 2005). Note-se que na promoção efetuada pelos organismos públicos ao destino Madeira, cuja intenção deveria ser sobretudo suscitar "no ser humano o desejo de experienciar, de sentir e conhecer as distintas culturas do lugar, ou seja, despertam nele o consumo pelas singularidades alheias" (Cravidão \& Marujo, 2012, p. 282), o turismo em espaço rural não figura em nenhum dos materiais promocionais, nem mesmo nos dossiers de imprensa que poderão ser consultados na página Web da Associação de Promoção da Região Autónoma da Madeira (AP Madeira, 2015).

Através do estudo efetuado apurámos que no universo do património cultural, a ilha da Madeira conta com 178 imóveis classificados (DRAC, 2012), dos quais 7 são monumentos nacionais (MN), 54 são monumentos de interesse público (IP), 114 são monumentos de interesse municipal (IM), dois são monumentos de valor cultural regional (VCR) e um foi considerado monumento de valor regional (VR). O concelho que reúne um maior número de imóveis classificados é o do Funchal (com 74), seguido pelos concelhos de Santa Cruz (com 29), Calheta (com 23), Machico (com 14), Ponta do Sol (com 14) e Santana (com 7), São Vicente (com 6), Câmara de Lobos (com 5), Ribeira Brava (com 4) e Porto Moniz (com 2).

Quanto às atividades culturais e tradicionais por concelho, destacaram-se os eventos de cariz religioso, com preponderância para os denominados «Arraiais Madeirenses» (Camacho, 1992). Estes são festas religiosas que primam por uma animação popular superior às restantes. São processos ideais para a transmissão cultural e de sociabilização que o visitante procura, cujo grau de competitividade interessa incentivar. Estes eventos permitem uma melhor integração do visitante TER com a população local, com a identidade do povo madeirense, em particular através da sua música, da sua indumentária e da sua gastronomia e vinhos, sendo considerados como "o momento por excelência de manifestação de muitos aspectos da cultura tradicional madeirense" (Camacho, 1992, p. 31). Na realidade, os eventos de caráter popular apresentam igualmente um valor acrescido na preservação e divulgação da identidade histórica e cultural da população madeirense, sendo internacionalmente reconhecido que as regiões deverão saber utilizar os "festivais e outros eventos para elevar o potencial turístico-cultural das suas comunidades" (WTO, 2006, p. 20). 
$\mathrm{Na}$ investigação efetuada não figuraram exposições temporárias, peças de teatro, bailados, concertos, conferências, congressos, lançamento de livros e outros, por serem eventos direcionados a públicos mais específicos.

Merece igualmente realce, a gastronomia tradicional madeirense, a qual manifesta uma viva ligação com os produtos provenientes do solo madeirense. Muitos dos ingredientes proveem da fauna e da flora do arquipélago. A singularidade da gastronomia madeirense reside nos hábitos da população rural, reflete a estrutura do seu quotidiano, é uma gastronomia de dimensão local limitada pelo território, pelo que traduz vivamente a identidade cultural da população madeirense, os seus costumes, a sua história, numa relação perfeita com os produtos regionais (Vieira, 2001).

O Vinho Madeira é mundialmente aceite como um vinho único. Possui uma história de cinco séculos de vivências, experiências e sabores que se transmitiram de gerações em gerações. Foi o responsável pela criação de uma paisagem vitícola madeirense, única a nível universal (Vieira, 2003).

No que concerne ao artesanato, entre a diversidade da oferta existente destaca-se o Bordado Madeira, quer pela sua qualidade e beleza, quer pela variedade de artigos que oferece ao visitante, em termos de funcionalidade e preço (Vieira, 2001; Walter \& Holman, 1987).

O Plano Estratégico Nacional do Turismo (2013-2015) distinguiu a Gastronomia e Vinhos pela sua relevância e potencial enquanto produto na aposta turística de uma região, quer pela tradição, quer pela qualidade dos produtos. A gastronomia madeirense e o vinho Madeira são heranças ancestrais comuns, são também fortes atrativos turístico-culturais e um património cultural que interessa ao visitante que procura o turismo em espaço rural.

O património cultural da Madeira, em especial no âmbito do turismo em espaço rural, deve ser entendido como um recurso turístico das localidades visitadas, uma vez que a "[v]alorização e a conservação das culturas locais, tradições e crenças são fundamentais para o desenvolvimento sustentável do turismo"(WTO, 2006, p. 73).

\subsection{Técnicas e Métodos}

Para a nossa área de estudo selecionámos a ilha da Madeira, como área primordial de investigação por ser a maior ilha do Arquipélago e na qual se localizam, em oito dos dez concelhos que a constituem, os empreendimentos de Turismo em Espaço Rural, as Casas de Campo, onde se alojariam os visitantes a estudar.

A seleção da modalidade Casas de Campo fundamentou-se numa forte motivação pessoal e em fatores que condicionaram os nossos critérios, entre os quais salientamos o número exíguo de unidades de alojamento TER na Madeira nas restantes modalidades e a preferência pelas unidades de alojamento/modalidade, na qual registámos maior número de responsáveis que acederam colaborar no presente estudo.

Partimos de uma investigação de carácter qualitativo com a finalidade de obter informação para compreender as posturas dos diferentes atores do turismo e o significado das suas práticas, a qual facilitou a elaboração do desenho da nossa investigação e possibilitou o relacionamento e a interpretação das diferentes variáveis, complementando a informação quantitativa disponível.

A investigação de carater exploratório sustentada pela revisão bibliográfica permitiu-nos proceder ao reconhecimento de uma realidade deficientemente estudada, estabelecer a hipótese para verificação ao longo do estudo, apurar conclusões sobre o perfil do visitante TER na Madeira, assim como estabelecer a inter-relação entre este sector turístico e o património madeirense, numa vertente de recurso turístico.

Elaborámos entrevistas semiestruturadas e inquéritos por questionário, realizados em profundidade, a um conjunto de informadores, em particular a empresários e turistas.

As entrevistas dirigidas aos proprietários ou representantes das unidades de alojamento foram essencialmente entrevistas formais semiestruturadas com perguntas abertas, focadas dominantemente nos conhecimentos e opiniões do entrevistado, características de uma situação de sondagem.

Os inquéritos por questionário dirigidos aos visitantes com questões de resposta fechada, subdividiam-se em três partes: a primeira, a visita à localidade; a segunda, o visitante e a terceira, o grau de satisfação. Na "visita à localidade» as questões incidiram sobre as motivações, organização da viagem e atividades durante a visita. A parte do "visitante» continha questões relacionadas com o perfil do visitante, desde o local de residência habitual, nacionalidade, faixa etária, nível de estudos, situação e ocupação profissional, entre outras. Quanto ao "grau de satisfação do visitante» houve a preocupação de conhecer o grau de satisfação em dois contextos: no da localidade visitada com enfoque especial para a questão do património e no do alojamento utilizado.

Os exemplares dos questionários a serem preenchidos pelos visitantes, entre os meses de junho e outubro de 2012, foram entregues aos proprietários ou representantes das Casas de Campo. Solicitámos aos proprietários/representantes que os questionários fossem entregues a todos os visitantes (nacionais e estrangeiros) que aceitassem participar na investigação e que pertencessem a uma mesma reserva de alojamento, excluindo visitantes menores. Reconhecemos a possibilidade de alguns constrangimentos nesta metodologia, no entanto pareceu-nos ser a que melhor responderia às necessidades da investigação. A inquirição direta aos visitantes seria uma tarefa incomportável, atendendo à dispersão geográfica dos estabelecimentos, à baixa taxa de ocupação-cama destes empreendimentos e ao horário irregular em que os visitantes se encontrariam no alojamento, uma vez que a maioria destes empreendimentos não oferece refeições principais. A estes motivos, acresceu uma outra ocorrência, a declaração por parte da maioria dos proprietários/representantes de não desejarem que os seus hóspedes fossem incomodados nas horas de descanso.

Das 34 Casas de Campo existentes na ilha Madeira, 16 casas aceitaram colaborar no presente estudo, o que assegurou uma boa representatividade da amostra $(47 \%)$, em relação ao número de empreendimentos e localização geográfica, assim como ao número de respostas às entrevistas, face ao universo em análise. 
As respostas dos visitantes aos inquéritos por questionário asseguraram igualmente uma boa representatividade da amostra, uma vez que as 164 respostas válidas ao «Questionário ao Visitante» representaram $44,1 \%$ da capacidade de alojamento total das Casas de Campo (372 camas) na ilha da Madeira.

O presente estudo foi complementado pela visita do investigador às Casas de Campo que acederam colaborar, tendo por objetivo aprofundar o seu conhecimento sobre a unidade de alojamento e o meio envolvente. Estas visitas permitiram-nos comparar aquilo que observávamos com os conhecimentos adquiridos anteriormente e retirar conclusões pertinentes que nos auxiliaram a descrever e interpretar a realidade em questão.

\section{Resultados e Discussão}

Ao longo dos séculos, a conceção de turismo sofreu diversas alterações, embora sempre ligada intrinsecamente a determinados pressupostos: viajar, conhecer outras culturas, visitar e admirar locais diferentes, aprender, relaxar, descansar, encontrar melhores condições para a cura de uma doença, etc.

Independentemente das definições aceites mundialmente, entre os estudiosos do Turismo, para a maioria daqueles que «fazem turismo", a prática é percecionada de forma individual, fruto de motivações pessoais, de diferentes práticas de estilo de vida e sobretudo dos distintos «sonhos» de cada indivíduo (Cunha, 2007; Prentice, 2004; OMT, 1998).

Os recursos de cada destino irão determinar a diversidade dos modelos de viagens turísticas desse destino, uma vez que esses atrativos serão os responsáveis pela motivação da visita (Cunha, 2007; Prentice, 2004; OMT, 1998).

Com base nas respostas dos visitantes aos inquéritos por questionário, é possível afirmar que os visitantes das "Casas de Campo» na ilha da Madeira eram maioritariamente casais e famílias, entre os 30 e os 59 anos, com um nível de estudos elevado, maioritariamente de nível superior. Compostos essencialmente por profissionais no ativo, com cargos diretivos ou profissões liberais, gozando de um nível económico-financeiro médio-elevado.

A duração média de estada dos visitantes situou-se entre 4 a 7 noites e para a maioria dos inquiridos, esta foi a sua primeira visita à Madeira, apenas $20 \%$ repetia a visita.

A principal motivação turística destes visitantes, tal como indica o Gráfico 1, foi "praticar turismo» (64,6\%). De acordo com a definição de Turismo, este tipo de resposta pode ser indicativo de que a maioria dos respondentes pretendia usufruir da oferta turística da região em geral, sem que existisse um único motivo específico para a realização da visita. No entanto, os dados revelaram que alguns visitantes possuíam motivações específicas ligadas, sobretudo, ao interesse pela natureza $(18,9 \%)$, ao interesse gastronómico $(6,1 \%)$, ao interesse pela zona $(5,5 \%)$ e ao interesse pela cultura tradicional (2,4\%). Estes dados confirmam conclusões já retiradas em outros estudos (Carneiro, Lima \& Silva, 2015 , p. 1230) e permitem-nos afirmar que $32,9 \%$ dos visitantes que procuram o turismo em espaço rural possuem motivações principais específicas, ligadas ao património natural e cultural da região visitada.
Gráfico 1 - Principal Motivo da Visita

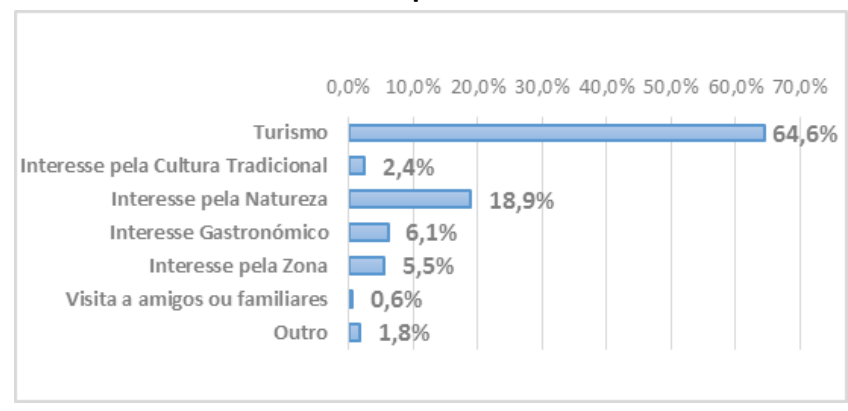

Fonte: Elaboração Própria a partir de dados fornecidos através do Inquérito por Questionário ao Visitante das Casas de Campo (2012).

A preferência por uma Unidade de Turismo em Espaço Rural (Gráfico 2) consumou-se através de uma questão de resposta múltipla. Na decisão dos visitantes ponderaram essencialmente os seguintes fatores: a "Tranquilidade e o Descanso» (64,6\% de respostas), seguido por dois outros fatores, o «Contacto com a Natureza» (48,2\% de respostas) e o "Contacto com a Cultura Local» (42,1\% de respostas). Em quarto plano surgiram, ex aequo, o «Ambiente Familiar» e o "Contacto com a População Local» (36\%).

\section{Gráfico 2 - Fator de Opção por uma Unidade Turística Rural}

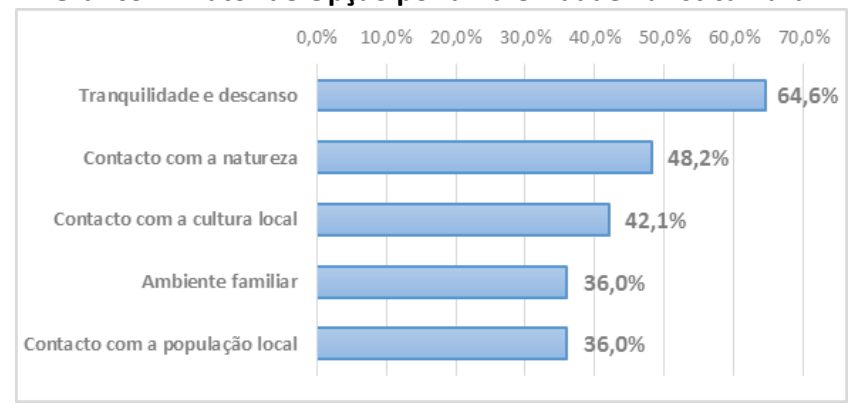

Fonte: Elaboração Própria a partir de dados fornecidos através do Inquérito por Questionário ao Visitante das Casas de Campo (2012).

Os resultados espelham o que Luís Mendes defende ao afirmar que este tipo de visitantes procura "os antípodas dos modos de vida que o meio urbano engendrou: a estabilidade, a continuidade, a autenticidade, a tranquilidade, a diferença, a humanização das relações, o contacto com a Natureza" (2010, p. 659).

Apesar do «Contacto com a Natureza» figurar em segundo plano e o «Contacto com a Cultura Local» em terceiro plano, gostaríamos de salientar que a diferença entre ambos, no que concerne ao número de respostas foi diminuta, na ordem dos $6,1 \%$, pelo que retrata o desejo destes visitantes em experienciar o contacto com a cultura local, motivação igualmente evocada por Luís Silva (2006, p. 307).

As atividades realizadas na Ilha (Gráfico 3) foram igualmente apuradas através de uma questão de resposta múltipla e incidiram sobretudo na natureza (82,9\% de respostas), no desejo de experimentar a gastronomia tradicional ( $78,7 \%$ de respostas), na compra de produtos tradicionais da zona ( $51,8 \%$ de respostas) e nas atividades culturais $(40,2 \%$ de respostas). Nesta perspetiva é fundamental relembrar que "o turismo é um fenómeno complexo e é seguramente um dos exemplos pioneiros da 'economia da experiência' em que hoje nos integramos. A valorização da 
experiência nunca como hoje foi tão elevada" (Inácio \& Patuleia, 2008, p. 94).

\section{Gráfico 3 - Atividades Realizadas durante a Visita}

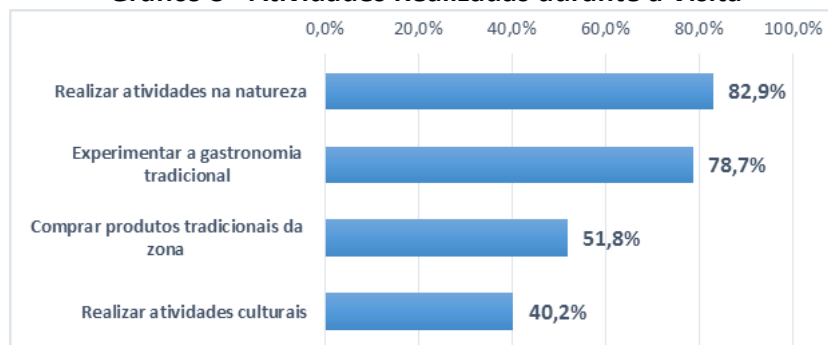

Fonte: Elaboração Própria a partir de dados fornecidos através do Inquérito por Questionário ao Visitante das Casas de Campo (2012).

Numa análise inicial, atendendo ao maior número de respostas somos levados a concluir que o património natural é mais procurado que o cultural. Numa perspetiva diferente, se considerarmos que "experimentar a gastronomia tradicional" (78,7\% de respostas) é uma atividade que se insere no património cultural de uma região, a conclusão será inversa, predominando a procura das atividades culturais relativamente às naturais. $\mathrm{Na}$ realidade, foram poucos os visitantes que responderam a uma única variável nesta questão, a maioria respondeu afirmativamente a duas variáveis: atividades na natureza e experimentar a gastronomia regional.

Ao longo das visitas às Casas de Campo e entrevistas aos proprietários/representantes colocámos algumas questões sobre os visitantes. Segundo os proprietários/representantes, os visitantes ocupavam o seu tempo essencialmente em três tipos de atividades, por ordem de importância decrescente consoante o número de respostas obtidas: «Atividades Culturais» (94\%), «Atividades na Natureza» (69\%), «Outras (Piscina/Leitura)» (31\%), valores que corroboram a análise anterior.

Comparativamente a outros perfis constatámos que existiam muitas similaridades entre os visitantes que procuram o turismo em espaço rural na Madeira e em outros países europeus (Qualitool, 2010; Neves, 2008; Silva, 2006; Lopes, 2005; Lourenço, 2005; Pinto, 2004; Dias, 2001; Carqueja, 1998). As especificidades encontradas residiram essencialmente em três aspetos, na faixa etária, nas motivações turísticas e na duração da visita, as quais, em nosso entender poderão estar diretamente relacionadas com os recursos turísticos da Madeira.

Nos estudos referenciados, à exceção do estudo de Luís Silva (2006), a «Tranquilidade e o Descanso» não figurava nas motivações principais, estas eram compostas essencialmente pela descoberta do território, pelo contacto com a natureza através de férias ativas e pelo caráter rural da localidade. Em estudos mais recentes (Mendes, 2010; Jesus, Kastenholz \& Figueiredo, 2008) a "Tranquilidade» começa a figurar como uma das motivações principais.

Um outro fator de opção pelo turismo rural que se distinguiu, nos visitantes da Madeira, foi o «Contacto com a Cultura Local». Para os visitantes que selecionaram esta opção a principal atividade que preferiram realizar na Madeira foi «Experimentar a Gastronomia Tradicional».
Ao longo da nossa investigação verificámos que as entidades responsáveis pela promoção turística da Madeira, a qual incide sobretudo no património natural da llha, não concedem um relevo especial à promoção do turismo em espaço rural e, os proprietários das "Casas de Campo» na divulgação dos seus empreendimentos seguem os mesmos parâmetros, predominando fortemente, quer nas descrições das casas, quer nas atividades sugeridas aos visitantes, informação relativa ao património natural em detrimento do património cultural. Julgamos que este facto, apesar de termos apurado a importância das atividades culturais nas motivações destes visitantes, possa ter interferido nos resultados dos questionários.

\section{Conclusão}

O estudo a que nos propusemos inicialmente pretendeu analisar a interligação entre o turismo em espaço rural, em particular as "Casas de Campo» na ilha da Madeira e o turismo cultural. As fontes consultadas revelam uma forte consensualidade na interligação entre estes dois tipos de turismo.

O fluxo turístico do TER na Madeira tem sido pouco estudado no campo da procura e da oferta turística. Estando o turismo em espaço rural intimamente relacionado com o movimento de pessoas, o seu estudo é fundamental para a compreensão dos fatores que o têm influenciado no tempo e no espaço. Conhecermos com maior rigor, qual o perfil do turista TER que visita a llha e sobretudo, quais as atrações turísticas principais no âmbito do património madeirense que motivam essa deslocação, é uma necessidade premente para o desenvolvimento sustentável do setor.

Com base nos resultados obtidos através dos questionários dirigidos aos visitantes e das diferentes entrevistas efetuadas, conseguimos concluir que a oferta turística das "Casas de Campo» na Madeira não se encontra devidamente adequada à procura turística.

Ainda no âmbito do património cultural a preservar e divulgar, gostaríamos de ressalvar a gastronomia, a sua continuidade tem estado dependente da sua transmissão e manutenção, de geração em geração. $O$ turismo tem desempenhado um papel fundamental na sua recuperação e preservação. Em grande parte, foi graças ao turismo que a gastronomia madeirense passou da esfera familiar para a comercial.

Os dados apresentados neste artigo são particularmente relevantes para o tópico deste estudo que se centra na relação entre o TER na modalidade Casas de Campo e o Turismo Cultural. Como foi possível constatar a ilha da Madeira detém recursos turísticos suficientes inseridos no património cultural, apesar da sua representatividade nos concelhos da Ilha não ser análoga, é amplamente reconhecido que a llha possui uma área diminuta, de $740 \mathrm{~km}^{2}$, com infraestruturas rodoviárias recentes que possibilitam o acesso a qualquer dos concelhos em períodos de tempo relativamente reduzidos, pelo que o património cultural da Madeira deve ser analisado como recurso turístico, numa ótica global e não fragmentada e indexada a um determinado concelho.

Sendo o critério definidor da oferta turística e neste caso particular, dos recursos turísticos, o da «utilização pelos 
visitantes», as atividades realizadas pelos usufruidores das Casas de Campo na Madeira, foram por ordem decrescente de importância: atividades na natureza ( $82,9 \%$ de respostas), experimentar a gastronomia regional $(78,7 \%$ de respostas) e realizar atividades culturais $(40,2 \%$ de respostas). Estes resultados permitem-nos validar a hipótese de partida, isto é, que as motivações turísticas destes visitantes não se fundamentam unicamente no património natural da Ilha, sendo a procura pelo património cultural uma realidade que retrata a aliança indissociável entre o Turismo Cultural e o TER na Madeira, um destino turístico promovido na esfera internacional prevalecentemente pelo seu património natural.

Atendendo a esta aliança indissociável na Madeira e à débil informação e divulgação dos recursos culturais da llha, concluímos que as entidades responsáveis deverão conceder uma maior relevância à vertente cultural como recurso turístico nas estratégias promocionais futuras do TER na Madeira, uma vez que "[u]m único indivíduo pode incluir-se em diferentes categorias em diferentes ocasiões. Sítios naturais e culturais são suscetíveis de receber [distintas] categorias de turistas [...], dependendo essa diversidade da natureza do local, da origem da maioria dos visitantes e da qualidade da informação geradora da motivação inicial da visita" (WTO, 2004b, p. 12).

Este caso de estudo focalizou-se na ilha da Madeira, no entanto, as conclusões gerais podem aplicar-se a outras regiões com caraterísticas similares, isto é, destinos turísticos em que a estratégia promocional se centralize no património natural. Futuros estudos que afiram a interligação entre o turismo cultural e o rural poderão enriquecer o conhecimento nesta área, contribuindo para o incremento da competitividade e da sustentabilidade do desenvolvimento do turismo em espaço rural.

\section{Referências}

Antunes, M. (1999). Teoria da Cultura. Lisboa: Edições Colibri.

AP Madeira (2015). Associação de Promoção da RAM. Retrieved May, 22, 2015 from http://www.madeirapromotionbureau.com.

Batista, A. \& Ferreira, A. (2010). O Turismo e a Cultura enquanto estratégias de regeneração de centros históricos. O caso de Alcácer do Sal. Revista Turismo \& Desenvolvimento, 13/14, 513-523.

Bel, F., Lacroix, A., Lyser, S., Rambonilaza, T. \& Turpin, N. (2015). Domestic demand for tourism in rural areas: Insights from summer stays in three French regions. Tourism Management, 46, 562-570.

Burnay, M. (2006). O Turismo Sustentável e o Turismo de Natureza Constrangimentos e Oportunidades. Revista Turismo \& Desenvolvimento, 6, 167-179.

Camacho, R. (1992). Festas e Arraiais da Madeira. Revista Xarabanda, 1, 31-36.

Carneiro, M., Lima, J. \& Silva, A. (2015). Landscape and the rural tourism experience: identifying key elements, addressing potential, and implications for the future. Journal of Sustainable Tourism, 23:8-9, 12171235, DOI: 10.1080/09669582.2015.1037840.

Carqueja, M. (1998). Turismo no espaço rural como alternativa de desenvolvimento: um estudo de caracterização e de avaliação da actividade em duas regiões do interior norte de Portugal [Texto policopiado]. Vila Real: Acessível na Biblioteca Nacional de Portugal.

Carvalho, A. (2008). Património e Diversidade: Algumas Questões para Reflexão. IV Encontro de História da Arte - IFCH/UNICAMP. Retrieved April, 20, 2012 from http://www.unicamp.br/chaa/eha/atas/2008.

Carvalho, I., Baptista, M. \& Costa, C. (2010). As Redes em Turismo Cultural: Um Olhar sobre a relação entre Turismo e Cultura. Revista Turismo \& Desenvolvimento, 13/14, 243-252.
Choay, F. (2008). A Alegoria do Património. Lisboa: Edições 70.

Cravidão, F. \& Marujo, M. (2012). Turismo e Lugares: uma visão geográfica. Revista Pasos, 10(3), 281-288. Retrieved March, 12, 2013 from http://www.pasosonline.org.

Crouch, D. (2013). The culture of leisure and tourism: engaging space and sustainability. In Cravidão, F. \& Santos, N. (Coord.), Turismo e Cultura, Destinos e Competitividade (21-34). Coimbra: Imprensa da Universidade de Coimbra.

Cunha, L. (2007). Introdução ao Turismo. 3a ed. Lisboa e São Paulo: Verbo. Dias, S. (2001). O Turismo em Espaço Rural e o seu Impacto no Desenvolvimento. Turismo em Espaço Rural. Porto: Vida Económica.

DRAC (2012). Listagem dos Imóveis Classificados - Região Autónoma da Madeira. Retrieved January, 10, 2012 from http://cultura.madeira-edu.pt. GConsulting (2005). Imagem da Madeira enquanto Destino Turístico. Retrieved May, 21, 2015 from http://www.visitmadeira.pt/pt-pt/infouteis/informacao-turistica-regional.

Henriques, C. (2008). Património Cultural e Turismo: Uma relação Simbiótica. Análise de dois percursos turístico-culturais: James Joyce e Fernando Pessoa. Revista Turismo \& Desenvolvimento, 10, 25-39.

Hernandez-Maestro, R. \& González-Benito,O. (2013). Rural Lodging Establishments as Drivers of Rural Development. Journal of Travel Research, 53(1), 83-95.

Huang, W., Beeco, A. Hallo, J. \& Norman, W. (2016). Bundling attractions for rural tourism development. Journal of Sustainable Tourism, DOI:10.1080/09669582.2015.1115510.

ICOMOS (1999). Carta Internacional sobre o Turismo Cultural. Retrieved April, 20, 2012 from http:// www.igespar.pt.

Inácio, A. \& Patuleia, M. (2008). Geoturismo, uma forma de Interpretação do Espaço Turístico: do Natural ao Urbano. Revista Turismo \& Desenvolvimento, 9, 91-102.

Jepson, D. \& Sharpley, R. (2015). More than sense of place? Exploring the emotional dimension of rural tourism experiences. Journal of Sustainable Tourism, 23:8-9, 1157-1178, DOI: 10.1080/09669582.2014.953543.

Jesus, L., Kastenholz, E. \& Figueiredo, E. (2008). A Oferta do Turismo no Espaço Rural, Estudo de Caso da Região Dão-Lafões. VII Colóquio Ibérico de Estudos Rurais - Cultura, Inovação e Território. Coimbra.

Lopes, R. (2005). Estudo de mercado e estratégias de segmentação para o turismo em espaço rural na Região do Parque Natural da Serra da Estrela [Texto policopiado]. Lisboa: Acessível na Biblioteca Nacional de Portugal.

Lourenço, F. (2005). Ruralidade, turismo e património: o turismo em espaço rural no norte do Alentejo: um estudo de caso [Texto policopiado]. Lisboa: Acessível na Biblioteca Nacional de Portugal.

MacDonald, R. \& Jolliffe, L. (2003). Cultural Rural Tourism, Evidence from Canada. Annals of Tourism Research, 30(2), 307-322, DOI: 10.1016/S01607383(02)00061-0.

Marujo, M. \& Ramos, F. (2008). Uma Visão Cultural do Turismo. Actas do Encontro Transfronteiriço Turismo Rural-Cultural e Desenvolvimento Sustentável. Reguengos de Monsaraz: Município.

Maurer, C. (2015). Digital Divide and Its Potential Impact on Cultural Tourism. In Katsoni, V. (eds.), Cultural Tourism in a Digital Era, First International Conference IACUDIT, Athens, 2014 (231-241). Switzerland: Springer.

Mendes, L. (2010). O Turismo na Produção Social do Espaço Rural Contemporâneo: Novas Procuras e a Emergência da Nobilitação Rural. Revista Turismo \& Desenvolvimento, 13/14, 655-663.

Neves, A. (Coord.) (2008). Estudo de Caracterização do Turismo no Espaço Rural e do Turismo de Natureza em Portugal. Lisboa: IESE, DGADR.

Nicely, A. \& Sydnor, S. (2015). Rural Tourism Development: Tackling a Culture of Local Nonparticipation in a Postslavery Society. Journal of Travel Research, 54(6), 717-729.

OMT (1998). Introducción al Turismo. Madrid: OMT.

Peña, A., Jamilena, D. \& Molina, M. (2012). The perceived value of the rural tourism stay and its effect on rural tourist behavior. Journal of Sustainable Tourism, 20:8, 1045-1065, DOI: 10.1080/09669582.2012.667108.

PENT (2013). Resolução do Conselho de Ministros no 24/2013, de 16 de abril, Presidência do Conselho de Ministros (Diário da República I Série Número 74, de 16 de abril de 2013). 
Perales, R. (2002). Rural Tourism in Spain. Annals of Tourism Research, 29(4), 1101-1110.

Pereira, G. (2009). Douro: História, Património e Enoturismo. Turismo: Enoturismo e Turismo em Espaço Rural - I Jornadas Internacionais sobre Enoturismo e Turismo em Espaço Rural. Maia: I.S.M.A.I.

Pérez, X. (2003). Patrimonialização e Transformação das Identidades Culturais. Portugal Chão. Oeiras: Celta.

Pinto, A. (2004). Turismo em Espaço Rural, Motivações e Práticas, Holandeses em Ferreira de Aves - Satão. Braga: Palimage.

Prentice, R. (2004). Motivação do Turista e Tipologias. Em Lew, A., Hall,C. \& Williams, A. (Coord.), Compêndio de Turismo. Lisboa: Instituto Piaget.

Qualitool (2010). Rural Tourism Quality Survey. Transfer of Quality Ensurance Tools for European Rural Tourism Sector. Retrieved April, 20, 2012

http://www.celotajs.lv/cont/proj/Leonardo2008/Leonardo2008_en.html.

Reis, R. (2013). As Recriações Históricas em Portugal - Perspetivas e Impatos. In Cravidão, F. \& Santos, N. (Coord.), Turismo e Cultura, Destinos e Competitividade (297-335). Coimbra: Imprensa da Universidade de Coimbra.

Rid, W., Ezeuduji, I. \& Pröbstl-Haider, U. (2014). Segmentation by motivation for rural tourism activities in The Gambia. Tourism Management, 40, 102-116.

Rodrigues, E. (2014). Turismo no Espaço Rural e Património. As Casas de Campo na llha da Madeira. Salamanca: Ediciones Universidad de Salamanca.

Santana-Jiménez, Y., Sun, Y., Hernandez, J. \& Suárez-Veja, R. (2015). The Influence of Remoteness and Isolation in the Rural Accommodation Rental Price among Eastern and Western Destinations. Journal of Travel Research, 54(3), 380-395.

Silva, I. (Coord.) (1985). A Madeira e o Turismo, Pequeno Esboço Histórico. Funchal: SRTC, DRAC.

Silva, L. (2006). Processos de mudança nos campos: o turismo em espaço rural [Texto policopiado]. Lisboa: Acessível na Biblioteca Nacional de Portugal.

UNWTO/UNESCO (2015). World Conference on Tourism and Culture: Building a New Partnership. Retrieved May, 10, 2015 from https://custom.cvent.com/E5C28A0D212A415D9AD3C8B699EBC072/files /8470b2c27d12494797caaa7cbc8e2c5e.pdf.

Vieira, A. (2003). A Vinha e o Vinho na História da Madeira, Séculos XV a $X X$. Funchal: CEHA.

Vieira, A. (Coord.) (2001). História da Madeira. Funchal: SRE.

Walter, C. \& Holman, K. (1987). The Embroidery of Madeira. New York: Union Square Press.

WTO (1997). International Tourism: A Global Perspective. Madrid: WTO.

WTO (2004a). Rural Tourism in Europe: Experiences, Development and Perspectives. Madrid: WTO.

WTO (2004b). Tourism Congestion Management at Natural and Cultural Sites. Madrid: WTO.

WTO (2006). Cultural Tourism and Local Communities. Madrid: WTO.

Recebido: 28.06.2015

Reenviado: 26.06.2016

Aceite: 28.06 .2016 